\title{
Papers
}

\section{Meta-analysis of parenteral nutrition versus enteral nutrition in patients with acute pancreatitis}

\author{
Paul E Marik, Gary P Zaloga
}

\begin{abstract}
Objective To compare the safety and clinical outcomes of enteral and parenteral nutrition in patients with acute pancreatitis.

Data sources Medline, Embase, Cochrane controlled trials register, and citation review of relevant primary and review articles.
\end{abstract}

Study selection Randomised controlled studies that compared enteral nutrition with parenteral nutrition in patients with acute pancreatitis. From 117 articles screened, six were identified as randomised controlled trials and were included for data extraction.

Data extraction Six studies with 263 participants were analysed. Descriptive and outcome data were extracted. Main outcome measures were infections, complications other than infections, operative interventions, length of hospital stay, and mortality. The meta-analysis was performed with the random effects model.

Data synthesis Enteral nutrition was associated with a significantly lower incidence of infections (relative risk 0.45 ; $95 \%$ confidence interval 0.26 to $0.78, \mathrm{P}=0.004)$, reduced surgical interventions to control pancreatitis $(0.48,0.22$ to 1.0 , $\mathrm{P}=0.05$ ), and a reduced length of hospital stay (mean reduction 2.9 days, 1.6 days to 4.3 days, $\mathrm{P}<0.001)$. There were no significant differences in mortality (relative risk $0.66,0.32$ to $1.37, \mathrm{P}=0.3)$ or non-infectious complications $(0.61,0.31$ to 1.22 , $\mathrm{P}=0.16$ ) between the two groups of patients.

Conclusions Enteral nutrition should be the preferred route of nutritional support in patients with acute pancreatitis.

\section{Introduction}

Nutritional support has become increasing recognised as an essential component of the management of critically ill patients. The benefits of the early initiation of enteral nutrition in surgical patients has now been clearly established. ${ }^{1-3}$ Furthermore, published data suggest that the gut is the optimum route of nutritional support in patients with an intact intestinal tract. ${ }^{4}$ Yet despite this information, total parenteral nutrition remains in widespread use, with many experts claiming equipoise between parenteral and enteral nutrition..$^{5-9}$

Acute pancreatitis results in a hypermetabolic, hyperdynamic, systemic inflammatory response syndrome that creates a highly catabolic stress state. Despite the lack of prospective data, gut rest (prohibiting enteral intake) with or without the provision of parenteral nutrition has become regarded as standard care in patients with acute pancreatitis. ${ }^{10}$ Recent evidence, however, suggests that enteral nutrition may be feasible (and perhaps desirable) in such patients. Animal studies have shown that the site in the gastrointestinal tract to which feedings are delivered determines whether the pancreas is stimulated and that jejunal feedings result in negligible increases in enzyme, bicarbonate, and volume output from the pancreas. ${ }^{11}{ }^{12}$ This observation has been confirmed in humans. ${ }^{13}$ Some experts suggest that enteral feeding stimulates lysosomal movement to the cell surface, minimising intracellular release of pancreatic enzymes, and may be therapeutic in patients with acute pancreatitis. In addition, enteral nutrition reduces production of proinflammatory mediators that may also have therapeutic potential in such patients.

The most severe complication of acute pancreatitis is pancreatic infection, which carries a mortality of up to $80 \%{ }^{14-17}$ Many studies report that total parenteral nutrition impairs humoral and cell mediated immunity, increases the vigour of the proinflammatory response, increases bacterial translocation, and increases infection rates in various critically ill patients. ${ }^{4}$ On the other hand, compared with total parenteral nutrition, enteral nutrition is associated with improved immune function and reduced infections. While several randomised controlled studies have been performed comparing total parenteral nutrition with enteral nutrition in patients with pancreatitis these studies have been underpowered and hence the differences were not always statistically significant. Furthermore, the magnitude of the treatment effect remains unknown. We therefore performed a metaanalysis of available studies that compared total parenteral nutrition with enteral nutrition to provide an estimate of the treatment effect on important clinical outcomes.

\section{Methods}

\section{Identification of trials}

We aimed to identify all relevant randomised controlled clinical trials that compared enteral with parenteral nutrition in patients with acute pancreatitis. A randomised controlled trial was defined as a trial in which participants were assigned prospectively to one of two interventions by random allocation. We used a multi-method approach to identify relevant studies for this review. Both authors independently searched the National Library of Medicine's Medline database for relevant studies in any language published from 1966 to January 2004 using the MeSH headings and keywords: enteral nutrition (explode) AND parenteral nutrition (explode) or TPN, AND pancreatitis, AND randomised controlled trials (publication type) or controlled clinical trials or clinical trials, randomised. In addition we searched Embase, the Cochrane controlled trials register, and the Cochrane Database of Systematic Reviews. Bibliographies of all selected articles and review articles that included information on 
nutrition in pancreatitis were reviewed for other relevant articles. In addition, we reviewed our personal files and contacted experts in the specialty. This search strategy was done iteratively until we did not find any new potential citations on review of the reference lists of retrieved articles.

\section{Study selection and data extraction}

To be included in the analysis trials had to be randomised clinical trials in patients admitted to hospital with acute pancreatitis. The intervention was enteral nutrition versus parenteral nutrition, and trials had to have as a primary outcome variable at least one of the following: number of infections, total number of non-infectious complications, number of surgical interventions, length of hospital stay, and hospital mortality.

\section{Data extraction}

We independently abstracted data from all studies using standardised forms. Data were abstracted on study design, setting, and population; severity of illness; the exact methods of nutritional support; and the outcome variables listed above. In calculating each outcome variable, we used intention to treat data (including all patients randomised). Disagreements regarding values or analysis were resolved by discussion and, if necessary, contact with the primary authors. Missing data were supplied by the primary authors. ${ }^{18} 19$

We used the APACHE II (acute physiology and chronic health evaluation) score, Ranson score, or Glasgow score to quantify the severity of pancreatitis. APACHE II is a general purpose scoring system for severity of illness that includes 12 physiological variables, age, and a chronic health score. ${ }^{20}$ An APACHE II score of $<10$ indicates mild disease with a low predicted mortality. The Ranson and Glasgow (or Imrie) scores predict the severity of pancreatitis. ${ }^{21}{ }^{22}$ The Ranson score includes 11 clinical and laboratory measurements available within 48 hours of admission. ${ }^{21}$ The Glasgow score is a modification of the Ranson system and includes nine clinical and laboratory variables. ${ }^{22} \mathrm{~A}$ Ranson or Glasgow score $\geq 3$ indicates severe pancreatitis. ${ }^{23}$

The methodological quality of the studies included in the meta-analysis was scored with the Jadad composite scale. ${ }^{24}{ }^{25}$ This is a 5 point quality scale, with low quality studies having a score of $\leq 2$ and high quality studies a score of $\geq 3 .{ }^{25}{ }^{26}$

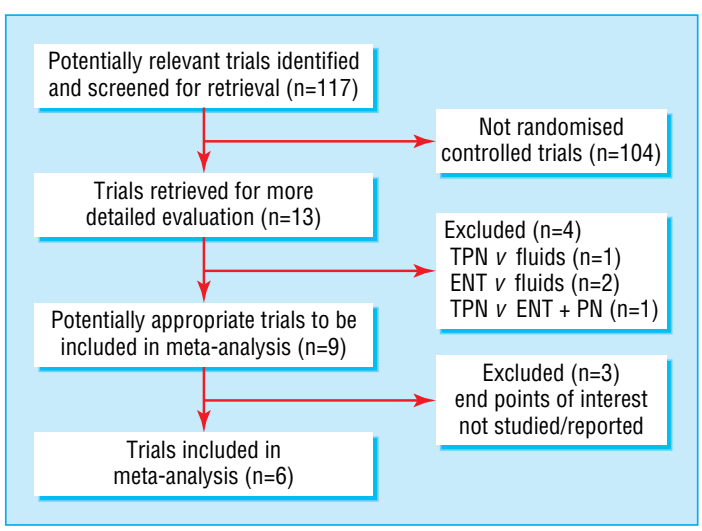

Fig 1 Process of study selection of randomised controlled trials (TPN=total parenteral nutrition; ENT=enteral nutrition; $\mathrm{PN}=$ parenteral nutrition)

\section{Data analysis}

Infections, complications other than infections, operative interventions, and mortality were binary variables, and length of hospital stay was a continuous variable. Study end points were calculated by intention to treat. The data analysis was performed using the random effects model with meta-analysis software (RevMan 4.1, Cochrane Collaboration, Oxford, and NCSS 2004, Kaysville, UT, USA). The relative risk and continuous data outcomes are presented with $95 \%$ confidence intervals. We tested heterogeneity between trials with $\chi^{2}$ tests, with $\mathrm{P} \leq 0.05$ indicating significant heterogeneity. ${ }^{27}$

\section{Results}

The search strategy generated 117 studies. From these, we identified 12 randomised clinical trials comparing enteral and parenteral nutrition. Only six randomised clinical trials fulfilled the criteria for consideration in the review. ${ }^{18}{ }^{19-31}$ Articles were excluded because parenteral nutrition was compared with conventional therapy (intravenous fluids alone), ${ }^{32}$ jejunal feeding was compared with conventional therapy, ${ }^{33-35}$ total parenteral nutrition was compared with the combination of enteral and

Table 1 Demographic data of studies included in meta-analysis. Figures are for enteral nutrition/total parenteral nutrition, and scores are given as means (SDs)

\begin{tabular}{|c|c|c|c|c|c|}
\hline & No of patients & Ranson criteria & Glasgow score & APACHE II & Siting of nasojejunal tube \\
\hline McClave, $1997^{28}$ & $16 / 16$ & $1.3(0.35) / 1.3(0.35)$ & - & - & Endoscopic \\
\hline Windsor, $1998^{29}$ & $16 / 18$ & - & $2 / 2$ & $8 / 9.5$ & Fluoroscopic* \\
\hline Kalfarentzos, $1997^{30}$ & $18 / 20$ & - & $4.2(0.9) / 4.6(1.1)$ & $12.7(2.6) / 11.8(1.9)$ & Fluoroscopic \\
\hline Abou-Assi, $2002^{19}$ & $26 / 27$ & $3.1(0.5) / 2.5(0.4)$ & - & - & Fluoroscopic/ endoscopic \\
\hline Olah, $2002^{18}$ & $41 / 48$ & - & $2.6(1.2) / 2.4(1.6)$ & - & Fluoroscopic \\
\hline Gupta, $2003^{31}$ & $8 / 9$ & - & - & $8 / 10$ & Blindt \\
\hline
\end{tabular}

*Patients with mild disease (Glasgow score $<3$ ) received oral nutrition.

†"Blind bedside technique."

Table 2 Outcome data of studies included in meta-analysis. Figures are for enteral nutrition/total parenteral nutrition

\begin{tabular}{|c|c|c|c|c|c|c|}
\hline & No of patients & Septic complications & Other complications & Surgical intervention & Length of stay & Mortality \\
\hline McClave, $1997^{28}$ & $16 / 16$ & $2 / 2$ & - & - & $9.7 / 11.9$ & $0 / 0$ \\
\hline Windsor, $1998^{29}$ & $16 / 18$ & $0 / 3$ & $0 / 5$ & $1 / 5$ & $12.5 / 15$ & $0 / 2$ \\
\hline Kalfarentzos, $1997^{30}$ & $18 / 20$ & $5 / 10$ & $3 / 5^{*}$ & $2 / 4$ & $40 / 39$ & $1 / 2$ \\
\hline Abou-Assi, $2002^{19}$ & $26 / 27$ & $1 / 9 \dagger$ & $13 / 17^{*}$ & $1 / 2$ & $14.2 / 18.4$ & $6 / 8$ \\
\hline Olah, $2002^{18}$ & $41 / 48$ & $5 / 13$ & $3 / 4$ & $5 / 11$ & $16.8 / 23.6$ & $2 / 4$ \\
\hline Gupta, $2003^{31}$ & $8 / 9$ & $0 / 2$ & $0 / 6 \ddagger$ & - & $7 / 10$ & $0 / 0$ \\
\hline
\end{tabular}

*Excluding hyperglycaemia.

$\dagger$ All central sepsis related to venous catheter.

†Organ failure. 
Table 3 Jadad quality score of trials included in meta-analysis ${ }^{24}$

\begin{tabular}{|c|c|c|c|c|c|}
\hline & Year & Randomisation method & Blinding & Withdrawals/drop outs accounted for & Jadad score \\
\hline McClave, $1997^{28}$ & 1997 & Not stated & None & Yes & 2 \\
\hline Windsor, $1998^{29}$ & 1998 & Odd/even hospital number & None & Yes & 1 \\
\hline Kalfarentzos, $1997^{30}$ & 1997 & Sealed numbered envelopes & None & Yes & 3 \\
\hline Abou-Assi, $2002^{19}$ & 2002 & Not stated & None & Yes & 2 \\
\hline Olah, $2002^{18}$ & 2002 & Birth date & None & Yes & 1 \\
\hline Gupta, $2003^{31}$ & 2003 & Sealed numbered envelopes & None & Yes & 3 \\
\hline
\end{tabular}

parenteral nutrition, ${ }^{36}$ and the end points of interest were not studied. ${ }^{36-39}$ Figure 1 shows the search process. A review of the bibliographies of all selected articles and review articles and communication with experts in the specialty failed to identify additional relevant articles. A total of 263 participants were enrolled in the six studies included in the meta-analysis (table 1). Table 2 shows the study outcome data. Table 3 shows the quality of the included studies as assessed by the Jadad score. We did not carry out subgroup analysis according to the Jadad score. ${ }^{40}$

The study by Olah and colleagues included a second phase, in which early jejunal feeding was combined with prophylactic imipenem. ${ }^{18}$ We did not include patients in this non-randomised third group in this meta-analysis. While all included studies randomised patients to enteral or parenteral nutritional support, selection of patients and study design differed somewhat between the studies. The inclusion criteria for all studies included patients admitted to hospital with acute pancreatitis characterised by abdominal pain with raised serum amylase and lipase activity. In all studies patients were enrolled within 48 hours after admission to hospital. Enteral nutrition was delivered through a nasojejunal tube that had been placed endoscopically or radiographically.

In the study by Gutpa et al, a dual lumen weighted nasojejunal tube was passed into the stomach at the bedside, with the position being verified radiographically. ${ }^{31}$ The study by Kalfarentzos et al included only patients with an Imrie score of $\geq 3$ or an APACHE II score of $\geq 8 .^{30}$ The study by Abou-Assi randomised patients with moderate to severe pancreatitis who had not improved clinically by 48 hours and were unable to tolerate resumption of normal feeding..$^{19}$ In the study by Windsor et al patients were stratified according to their admission Imrie score. ${ }^{29}$ In this study patients with mild/moderate disease $(<3$ Imrie points) received enteral feeding in the form of oral nutritional supplements, while patients with an Imrie score of $\geq 3$ received enteral nutrition through a nasojejunal tube. McClave and coworkers compared early enteral versus parenteral nutrition in patients with mild pancreatitis. ${ }^{28}$ In three studies nutritional support was initiated within 48 hours of admission to hospital. ${ }^{18} 28{ }^{30}$ In two studies a 48 hour enrolment period was followed by the nutritional support period. ${ }^{19}{ }^{29}$ Indications for operative intervention in all studies included persistent or deteriorating organ failure despite maximal intensive care, verified infected pancreatic necrosis, and large symptomatic or infected pseudocyst formation.

\section{Primary outcomes}

Figure 2 shows the relative risks and 95\% confidence intervals for infections, complications other than infections, surgical intervention, and mortality.

Infections-Information on the incidence of infections was available for all the studies included in the meta-analysis. Infections recorded included pneumonia, abdominal abscess, pancreatic abscess, wound infections, and blood stream infection. Overall, there was a significantly lower risk of infection in the patients who received enteral nutrition compared with those who received parenteral nutrition (relative risk of $0.45,95 \%$ confidence interval 0.26 to $0.78, \mathrm{P}=0.004$, fig 3 ). The test result for heterogeneity between the studies was not significant $(\mathrm{P}=0.59)$.

Complications other than infections-Five studies reported on complications other than infections, including adult respiratory distress syndrome, multi-organ failure, acute pseudocysts, and pancreatic fistula. There was no significant difference in the incidence between the enteral and total parenteral nutrition group (0.61, 0.31 to $1.22, \mathrm{P}=0.16)$.

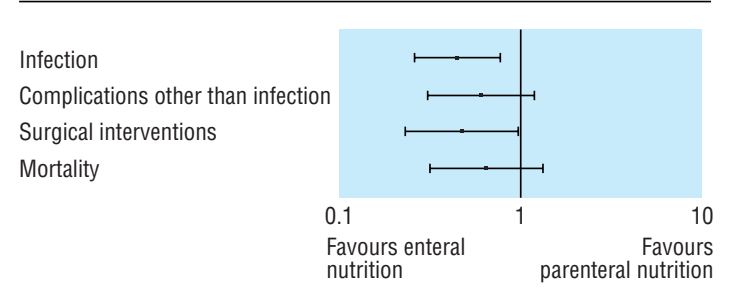

Fig 2 Risk of infection, complications other than infection, surgical intervention, and mortality; results from meta-analyses of randomised trials comparing enteral with parenteral nutrition in pancreatitis

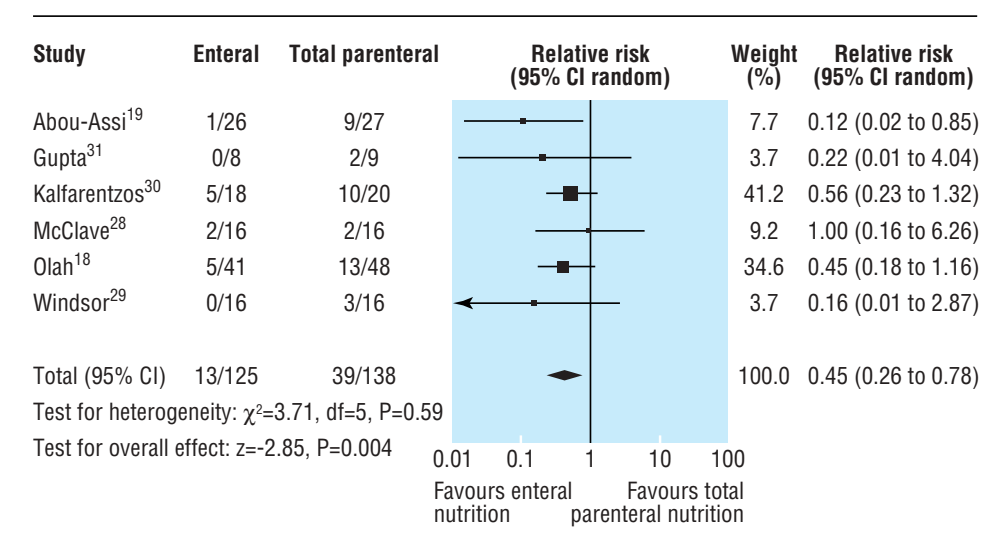

Fig 3 Random effects model of relative risk (95\% confidence interval) of infections associated with enteral feeding compared with parenteral nutrition 
Surgical interventions-Four studies reported on the need for surgical intervention for the management of pancreatitis. The requirement for surgery was significantly lower in the patients fed enterally $(0.48,0.23$ to $0.99, \mathrm{P}=0.05)$. The test result for heterogeneity was not significant $\left(\chi^{2}=0.62, \mathrm{P}=0.89\right)$.

Length of hospital stay-All studies included in the metaanalysis provided information on length of hospital stay, which was significantly shorter in the enteral nutrition group (mean reduction of 2.9 days, 1.6 days to 4.3 days; $\mathrm{P}<0.001$ ). There was, however, significant heterogeneity between studies $\left(\chi^{2}=16.5\right.$, $\mathrm{P}=0.0056)$.

Mortality-All studies reported on hospital mortality. There was no significant difference in hospital mortality between the enteral and total parenteral nutrition groups (relative risk 0.66, 0.32 to $1.37, \mathrm{P}=0.3)$.

\section{Discussion}

This meta-analysis shows that in patients with acute pancreatitis, total parenteral nutrition, as compared with enteral nutrition, significantly increases the risk of infective complications, increases the likelihood of a surgical intervention (to control pancreatic infection), and increases the length of hospital stay. The detrimental effects of total parenteral nutrition were associated with a trend towards increased complications other than infections and a higher mortality. Importantly, the results are internally consistent and all outcomes favour the enterally fed groups.

\section{Parenteral nutrition and infections}

The finding that parenteral nutrition increases infections in patients with pancreatitis is not unexpected and is supported by a large body of experimental and clinical data. Experimental studies show that total parenteral nutrition (enteric starvation) results in rapid and severe atrophy of lymphoid tissue associated with the gut (GALT) and increases bacterial translocation. ${ }^{41-44}$ Lymphoid tissue associated with the gut is the source of most mucosal immunity in humans. In addition, total parenteral nutrition is associated with impaired $\mathrm{B}$ and $\mathrm{T}$ cell lymphocyte function, altered leucocyte chemotaxis, impaired phagocytosis, and impaired bacterial and fungal killing. ${ }^{45-49}$ Experimental models of sepsis have shown a significantly higher mortality in animals receiving parenteral compared with enteral nutrition. ${ }^{50-53}$ These experimental data are supported by clinical studies, which have consistently shown a higher risk of infection in patients receiving total parenteral nutrition. ${ }^{194-59}$ Nonrandomised clinical studies of use of total parenteral nutrition in patients with acute pancreatitis also suggest increased infection rates. ${ }^{60-62}$

\section{Parenteral nutrition enhances the proinflammatory response}

While parenteral nutrition is associated with impaired innate and acquired immunity, predisposing patients to infection, it is also associated with a more pronounced proinflammatory response. Clinical and experimental studies have shown higher levels of both local and systemic proinflammatory mediators with parenteral compared with enteral nutrition. ${ }^{29}{ }^{53}$ Lin and coworkers found higher concentrations of interleukin 6 and interleukin 8 after colorectal surgery in patients receiving total parenteral nutrition compared with those fed enterally. ${ }^{63}$ Similarly Gianotti and coworkers found higher concentrations of interleukin 6 in patients undergoing major abdominal surgery for malignant neoplasms who received total parenteral nutrition compared with enteral nutrition. ${ }^{59}$ Fong and colleagues challenged healthy volunteers with endotoxin after they had received enteral feedings or total parenteral nutrition (without oral intake) for seven days. ${ }^{64}$ In this study, circulating concentrations of tumour necrosis factor $\alpha$ and $\mathrm{C}$ reactive protein were significantly higher in the total parenteral nutrition group. In the study by Windsor et al, included in our meta-analysis, there was a significant fall in the serum concentration of $\mathrm{C}$ reactive protein after enteral nutritional support, while there was no significant change in this variable in the parenterally fed group. ${ }^{29}$ An enhanced proinflammatory response in patients receiving total parenteral nutrition may partly explain the associated increased morbidity we observed.

\section{Pancreatic infections and bacterial translocation}

The most severe complication of acute pancreatitis is pancreatic infection. ${ }^{14-17}$ The risk of pancreatic infection is related to the extent of pancreatic necrosis and therefore the severity of the disease. The finding that the microorganisms causing pancreatic infection are common enteric pathogens implies that bacterial translocation from the intestinal tract to pancreas may have a role in the pathogenesis of sepsis induced by pancreatitis. ${ }^{14-17}$ 65-67 Lack of enteral feeding results in atrophy of the gastrointestinal mucosa, bacterial overgrowth, increased intestinal permeability, and translocation of bacteria or bacterial products into the circulation. ${ }^{68-76}$ Total parenteral nutrition may therefore promote bacterial translocation in patients with pancreatitis. In an experimental model of pancreatitis, compared with total parenteral nutrition, enteral nutrition reduced systemic plasma endotoxin, bacterial translocation to the portal and systemic blood, and bacterial colony counts in the mesenteric lymph nodes, pancreas, and lung. ${ }^{77}$ In addition, changes in enteral nutrient supply, osmolality, or $\mathrm{pH}$ with total parenteral nutrition may induce bacteria to express virulence genes that enhance bacterial adhesion and translocation or the production of local toxins that may act locally or systemically. ${ }^{78-81}$ Enteral nutrition, on the other hand, may switch off these virulence genes.

The studies reported in this analysis provided enteral nutrition through feeding tubes in the small bowel. Although the exact location of all tubes was not reported, most were stated to be in the jejunal location. It is known that pancreatic stimulation from enteral nutrients decreases as the feeding site moves down the bowel. Thus, it is unclear whether similar results would occur with more proximal feeding sites such as the stomach.

Most cases of acute pancreatitis are mild and self limiting, with serum enzyme activities returning toward normal within two to four days. Indeed, in the study by Abou-Assi et al, $87 \%$ of patients with pancreatitis admitted to their hospital over a 12 month period had mild pancreatitis ( $<3$ Ranson criteria), with $75 \%$ of patients being able to resume oral feeding within 48 hours after admission. ${ }^{19}$ We suggest placement of a jejunal feeding tube and the initiation of early enteral feeding in patients with moderate and severe pancreatitis ( $>3$ Ranson criteria). In patients with mild pancreatitis placement of a jejunal feeding tube and the initiation of enteral feeding should be considered in those patients who are unable to resume oral feeding after 48 hours of conservative therapy. Previously well nourished patients with mild pancreatitis who can resume oral intake within a few days may not benefit from enteral tube feeding. On the other hand, it is likely that previously malnourished patients and patients unable to resume oral intake within a few days would benefit from nutritional support.

\section{Limitations of study}

This systematic review has several limitations. The studies included are of relatively poor quality, with four of the six studies 


\section{What is already known on this topic}

Gut rest, with or without parenteral nutrition, is considered to be the standard care in patients with acute pancreatitis

In patients with an intact gastrointestinal tract, enteral nutrition is the preferred route of nutritional support

Parenteral nutrition is immunosuppressive and proinflammatory and may be deleterious in patients with pancreatitis

\section{What this study adds}

Compared with enteral nutrition, parenteral nutrition significantly increases the risk of infections and the requirement for surgical interventions in patients with acute pancreatitis

The early initiation of enteral nutrition should be considered as standard in patients with severe pancreatitis

having a Jadad score of $<3 .{ }^{24}$ None of the studies included in this meta-analysis were blinded. Studies with inadequate concealment of allocation may overestimate the intervention effect. ${ }^{82}$ However, it would be extremely difficult, if not impossible, to conceal the route of nutritional support even if placebo formulations were used. An additional limitation is the small number of patients that were included in the analysis $(n=263)$. The overall small sample size led to wide confidence intervals. Furthermore, the included studies had differing inclusion and exclusion criteria (and therefore differing severity of illness). The difference in severity of disease may explain the heterogeneity in the length of stay between studies. Furthermore, it is possible that studies with negative results, which showed no trend in favour of either intervention, may remain unpublished, leading to publication bias. The limitations of the individual included studies restrict the strength of the conclusion that can be drawn from this review. However, our results are supported by an extensive body of experimental and clinical data, which has shown the adverse effects of parenteral compared with enteral nutrition (such as immune compromise, increased risk of infections, exaggerated proinflammatory response, metabolic complications, depletion of antioxidants, gut atrophy). $.^{29} 41-536368-76$

In conclusion, although the available data are limited in terms of numbers and methodological quality, the best available evidence does not support the use of total parenteral nutrition in patients with acute pancreatitis. This conclusion is supported by a large body of experimental and clinical data and with the underlying pathophysiology of pancreatitis.

Contributors: Both authors selected studies, extracted and analysed data, and wrote the paper. PEM is guarantor.

Funding: None.

Competing interests: None declared.

Ethical approval: Not required.

1 Lewis SJ, Egger M, Sylvester PA, Thomas S. Early enteral feeding versus "nil by mouth" after gastrointestinal surgery: systematic review and meta-analysis of controlled trials. BMJ 2001;323:773-6.

2 Marik PE, Zaloga GP. Early enteral nutrition in acutely ill patients: a systematic review. Crit Care Med 2001;29:2264-70.

3 Silk DB, Gow NM. Postoperative starvation after gastrointestinal surgery. Early feeding is beneficial. BMJ 2001;323:761-2

4 Marik PE, Pinsky MR. Death by total parenteral nutrition. Intensive Care Med 2003;29:867-9.

5 Varga P, Griffiths R, Chiolero R, Nitenberg G, Leverve X, Pertkiewicz, et al. Is parenteral nutrition guilty? Intensive Care Med 2003;29:1861-4.
6 Dominguez-Cherit G, Borunda D, Rivero-Sigarroa E. Total parenteral nutrition. Curr Opin Crit Care 2002;8:285-9.

7 Jeejeebhoy KN. Total parenteral nutrition: potion or poison? Am J Clin Nutr 2001;74:160-3.

8 Bistrian BR. Update on total parenteral nutrition. Am J Clin Nutr 2001;74:153-4.

9 Lipman TO. Grains or veins: is enteral nutrition really better than parenteral nutrition? A look at the evidence. JPEN J Parenter Enteral Nutr 1998;22:167-82.

10 Yeo CJ, Cameron JL. The pancreas. In: Sabiston DC, Lyerly HK. eds. Textbook of surgery. The biological basis of modern surgical practice. Philadelphia: WB Saunders, 1997:1151-86.

11 Ragins H, Levenson SM, Signer R, Stamford W, Seifter E. Intrajejunal administration of an elemental diet at neutral $\mathrm{pH}$ avoids pancreatic stimulation. Studies in dog and man. Am J Surg 1973;126:606-14.

12 Cassim MM, Allardyce DB. Pancreatic secretion in response to jejunal feeding of elemental diet. Ann Surg 1974;180:228-31.

13 Vu MK, van der Veek PP, Frolich M, Souverijn JH, Biemond I, Lamers CB, et al. Does jejunal feeding activate exocrine pancreatic secretion? Eur J Clin Invest 1999;29:1053-9.

14 Renner IG, Savage WT, III, Pantoja JL, Renner VJ. Death due to acute pancreatitis. A retrospective analysis of 405 autopsy cases. Dig Dis Sci 1985;30:1005-18.

15 Lumsden A, Bradley EL, III. Secondary pancreatic infections. Surg Gynecol Obstet 1990;170:459-67.

16 Beger HG, Bittner R, Block S, Buchler M. Bacterial contamination of pancreatic necrosis. A prospective clinical study. Gastroenterology 1986;91:433-8.

17 Medich DS, Lee TK, Melhem MF, Rowe MI, Schraut WH, Lee KK. Pathogenesis of pancreatic sepsis. Am J Surg 1993;165:46-50.

18 Olah A, Pardavi G, Belagyi T, Nagy A, Issekutz A, Mohamed GE. Early nasojejunal feeding in acute pancreatitis is associated with a lower complication rate. Nutrition 2002;18:259-62.

19 Abou-Assi S, Craig K, O'Keefe SJ. Hypocaloric jejunal feeding is better than total parenteral nutrition in acute pancreatitis: results of a randomized comparative study. Am J Gastroenterol 2002;97:2255-62.

20 Knaus WA, Draper EA, Wagner DP, Zimmerman JE. APACHE II: a severity of disease classification system. Crit Care Med 1985;13:818-28.

21 Ranson JH, Rifkind KM, Roses DF, Fink SD, Eng K, Spencer FC. Prognostic signs and the role of operative management in acute pancreatitis. Surg Gynecol Obstet 1974:139:69-81.

22 Imrie CW, Benjamin IS, Ferguson JC, McKay AJ, Mackenzie I, O'Neill J, et al. A singlecentre double-blind trial of Trasylol therapy in primary acute pancreatitis. $\mathrm{Br} J$ Surg 1978;65:337-41.

23 Blamey SL, Imrie CW, O’Neill J, Gilmour WH, Carter DC. Prognostic factors in acute pancreatitis. Gut 1984;25:1340-6.

24 Jadad AR, Moore RA, Carroll D, Jenkinson C, Reynolds DJ, Gavaghan DJ, et al. Assessing the quality of reports of randomized clinical trials: is blinding necessary? Control Clin Trials 1996;17:1-12

25 Kjaergard LL, Villumsen J, Gluud C. Reported methodologic quality and discrepancies between large and small randomized trials in meta-analyses. Ann Intern Med 2001;135:982-9

26 Moher D, Pham B, Jones A, Cook DJ, Jadad AR, Moher M, et al. Does quality of reports of randomised trials affect estimates of intervention efficacy reported in meta-analyses? Lancet 1998;352:609-13.

27 Oxman AD, Cook DJ, Guyatt GH. Users guide to the medical literature. VI. How to use an overview. Evidence-based working group. JAMA 1994;272:1367-71.

28 McClave SA, Greene LM, Snider HL, Makk JL, Cheadle WG, Owens NA, et al Comparison of the safety of early enteral vs parenteral nutrition in mild acute pancreatitis. JPEN J Parenter Enteral Nutr 1997;21:14-20.

29 Windsor AC, Kanwar S, Li AG, Barnes E, Githrie JA, Spark JI, et al. Compared with parenteral nutrition, enteral feeding attenuates the acute phase response and improves disease severity in acute pancreatitis. Gut 1998;42:431-435.

30 Kalfarentzos F, Kehagias J, Mead N, Kokkinis K, Gogos CA. Enteral nutrition is superior to parenteral nutrition in severe acute pancreatitis: results of a randomized prospective trial. BrJ Surg 1997;84:1665-9.

31 Gupta R, Patel K, Calder PC, Yaqoob P, Primrose JN, Johnson CD. A randomised clinical trial to assess the effect of total enteral and total parenteral nutritional support on metabolic, inflammatory and oxidative markers in patients with predicted severe acute pancreatitis (APACHE II > 6). Pancreatology 2003;3:406-13.

32 Sax HC, Warner BW, Talamini MA, Hamilton FN, Bell RH Jr, Fischer JE, et al. Early total parenteral nutrition in acute pancreatitis: lack of beneficial effects. Am J Surg parenteral nutrition

33 Pupelis G, Selga G, Austrums E, Kaminski A. Jejunal feeding, even when instituted late, improves outcomes in patients with severe pancreatitis and peritonitis. Nutrition 2001; 17:91-4

34 Pupelis G, Austrums E, Jansone A, Sprucs R, Wehbi H. Randomised trial of safety and efficacy of postoperative enteral feeding in patients with severe pancreatitis: preliminary report. Eur J Surg 2000;166:383-7.

35 Powell JJ, Murchison JT, Fearson KC, Ross JA, Siriwardena AK. Randomized controlled trial of the effect of early enteral nutrition on markers of the inflammatory response in predicted severe acute pancreatitis. Br J Surg 2000;87:1375-81

36 Zhao G, Wang CY, Wang F, Xiong JX. Clinical study on nutrition support in patients Zhao G, Wang CY, Wang F, Xiong JX. Clinical study on nutrition
with severe acute pancreatitis. World J Gastroenterol 2003;9:2105-8.

37 Hernandez-Aranda JC, Gallo-Chico B, Ramirez-Barba EJ. Nutritional support in severe Hernandez-Aranda JC, Gallo-Chico B, Ramirez-Barba EJ. Nutritional support in

38 Bodoky G, Harsanyi L, Pap A. The effect of early postoperative nutrition on exocrine pancreatic function. Acta Chirurgica Hungarica 1992;33:23-35.

39 Craig CP, Connelley S. Effect of intensive care unit nosocomial pneumonia on duration and mortality. Am J Infect Control 1984;12:233-8.

40 Balk EM, Bonis PA, Moskowitz H, Schmid CH, Ioannidis JP, Wang C, et al. Correlation of quality measures with estimates of treatment effect in meta-analyses of randomized controlled trials. JAMA 2002;287:2973-82.

41 Kudsk KA, Li J, Renegar KB. Loss of upper respiratory tract immunity with parenteral feeding. Ann Surg 1996;223:629-35.

42 Janu P, Li J, Renegar KB, Kudsk KA. Recovery of gut-associated lymphoid tissue and upper respiratory tract immunity after parenteral nutrition. Ann Surg 1997;225:707-15. 43 King BK, Li J, Kudsk KA. A temporal study of TPN-induced changes in gut-associated lymphoid tissue and mucosal immunity. Arch Surg 1997;132:1303-9. 
44 Li J, Kudsk KA, Gocinski B, Dent D, Glezer J, Langkamp-Henken B. Effects of parenteral and enteral nutrition on gut-associated lymphoid tissue. J Trauma $1995 ; 39: 44-51$

45 Alverdy JC, Burke D. Total parenteral nutrition: iatrogenic immunosuppression. Nutrition 1992;8:359-65.

46 Waitzberg DL, Lotierzo PH, Logullo AF, Torrinhas RS, Pereira CC, Meier R. Parenteral lipid emulsions and phagocytic systems. Br J Nutr 2002;87(suppl 1):S49-57.

47 Maderazo EG, Woronick CL, Quercia RA, Hickingbotham N, Drezner AD. The inhibitory effect of parenteral nutrition on recovery of neutrophil locomotory function in tory effect of parenteral nutrition on recov

48 Granato D, Blum S, Rossle C, Le Boucher J, Malnoe A, Dutot G. Effects of parenteral lipid emulsions with different fatty acid composition on immune cell functions in vitro. JPEN J Parenter Enteral Nutr 2000;24:113-8.

49 Okada Y, Papp E, Klein NJ, Pierro A. Total parenteral nutrition directly impair cytokine production after bacterial challenge. J Pediatr Surg 1999;34:277-80.

50 Petersen SR, Kudsk KA, Carpenter G, Sheldon GE. Malnutrition and immunocompetence: increased mortality following an infectious challenge during hyperalimentation. J Trauma 1981;21:528-33.

51 Kudsk KA, Carpenter G, Petersen S, Sheldon GF. Effect of enteral and parenteral feeding in malnourished rats with E coli-hemoglobin adjuvant peritonitis. J Surg Res $1981 \cdot 31: 105-10$

52 Kudsk KA, Stone JM, Carpenter G, Sheldon GF. Enteral and parenteral feeding influences mortality after hemoglobin-E coli peritonitis in normal rats. J Trauma 1983;23:605-9.

53 Lin MT, Saito H, Fukushima R, Inaba T, Fukatsu K, Inoue T, et al. Route of nutritional supply influences local, systemic, and remote organ responses to intraperitoneal bacterial challenge. Ann Surg 1996;223:84-93

54 Perioperative total parenteral nutrition in surgical patients. The Veterans Affairs Total Parenteral Nutrition Cooperative Study Group. N Engl J Med 1991:325:525-32.

55 Parenteral nutrition in patients receiving cancer chemotherapy. American College of Physicians. Ann Intern Med 1989;110:734-6.

56 Kudsk KA, Croce MA, Fabian TC, Minard G, Tolley EA, Poret HA, et al. Enteral versus parenteral feeding. Effects on septic morbidity after blunt and penetrating abdominal trauma. Ann Surg 1992;215:503-11.

57 Moore FA, Feliciano DV, Andrassy RJ, McArdle AH, Booth FV, Morgenstein-Wagner TB, et al. Early enteral feeding, compared with parenteral, reduces postoperative septic complications. The results of a meta-analysis. Ann Surg 1992;216:172-83.

58 Braga M, Gianotti L, Vignali A, Cestari A, Bisagni P, Di Carlo V. Artificial nutrition after major abdominal surgery: impact of route of administration and composition of the diet Crit Care Med 1998:26:24-30.

59 Gianotti L, Braga M, Vignali A, Balzano G, Zerbi A, Bisagni P, et al. Effect of route of delivery and formulation of postoperative nutritional support in patients undergoing major operations for malignant neoplasms. Arch Surg 1997;132:1222-1229.

60 Goodgame JT, Fischer JE. Parenteral nutrition in the treatment of acute pancreatitis: effect on complications and mortality. Ann Surg 1977;186:651-8.

61 Grant JP, James S, Grabowski V, Trexler KM. Total parenteral nutrition in pancreatic disease. Ann Surg 1984;200:627-31.

62 Kalfarentzos FE, Karavias DD, Karatzas TM, Alevizatos BA, Androulakis JA. Total parenteral nutrition in severe acute pancreatitis. J Am Coll Nutr 1991;10:156-62.

63 Lin MT, Saito H, Fukushima R, Inaba T, Fukatsu K, Inoue T, et al. Preoperative total parenteral nutrition influences postoperative systemic cytokine responses after colorectal surgery. Nutrition 1997;13:8-12.

64 Fong YM, Marano MA, Barber A, He W, Moldawer LL, Bushman ED, et al. Tota parenteral nutrition and bowel rest modify the metabolic response to endotoxin in humans. Ann Surg 1989;210:449-56.
65 Runkel NS, Moody FG, Smith GS, Rodriguez LF, LaRocco MT, Miller TA. The role of the gut in the development of sepsis in acute pancreatitis. J Surg Res 1991;51:18-23. 66 Cicalese L, Sahai A, Sileri P, Rastellini C, Subbotin V, Ford H, et al. Acute pancreatitis and bacterial translocation. Dig Dis Sci 2001;46:1127-32.

67 Nettelbladt CG, Katouli M, Bark T, Svenberg T, Mollby R, Ljungqvist O. Evidence of bacterial translocation in fatal hemorrhagic pancreatitis. J Trauma 2000;48:314-5.

68 Hadfield RJ, Sinclair DG, Houldsworth PE, Evans TW. Effects of enteral and parenteral nutrition on gut mucosal permeability in the critically ill. Am J Respir Crit Care Med $1995 ; 152: 1545-8$.

69 Nakasaki H, Mitomi T, Tajima T, Ohnishi N, Fujii K. Gut bacterial translocation during total parenteral nutrition in experimental rats and its countermeasure. Am J Surg 1998;175:38-43.

70 Shou J, Lappin J, Minnard EA, Daly JM. Total parenteral nutrition, bacterial translocation, and host immune function. Am J Surg 1994;167:145-50.

71 Qiu JG, Delany HM, Teh EL, Freundlich L. Gliedman ML, Steinberg JJ, et al. Contrasting effects of identical nutrients given parenterally or enterally after $70 \%$ hepatectomy: bacterial translocation. Nutrition 1997;13:431-7.

72 Levine GM, Deren JJ, Steiger E, Zinno R. Role of oral intake in maintenance of gut mass and disaccharide activity. Gastroenterology 1974;67:975-82.

73 Deitch EA. Bacterial translocation of the gut flora. J Trauma 1990;30:S184-9.

74 Langkamp-Henken B, Donovan TB, Pate LM, Maull CD, Kudsk KA. Increased intestinal permeability following blunt and penetrating trauma. Crit Care Med 1995.23:660-4

75 Deitch FA, Winterton J, Li M, Berg R. The gut as a portal of entry for bacteremia. Role of protein malnutrition. Ann Surg 1987;205:681-92.

76 Sugiura T, Tashiro T, Yamamori H, Takagi K, Hayashi N, Habashi T, et al. Effects of total parenteral nutrition on endotoxin translocation and extent of the stress response in burned rats. Nutrition 1999;15:570-5.

77 Qin HL, Su ZD, Hu LG, Ding ZX, Lin QT. Effect of early intrajejunal nutrition on pancreatic pathological features and gut barrier function in dogs with acute pancreatitis. Clin Nutr 2002;21:469-73.

78 Alverdy JC, Laughlin RS, Wu L. Influence of the critically ill state on host-pathogen interactions within the intestine: gut-derived sepsis redefined. Crit Care Med 2003;31:598-607.

79 Cheng LW, Schneewind O. Type III machines of Gram-negative bacteria: delivering the goods. Trends Microbiol 2000;8:214-20.

80 Saulino ET, Bullitt E, Hultgren SJ. Snapshots of usher-mediated protein secretion and ordered pilus assembly. Proc Natl Acad Sci U S A 2000;97:9240-5.

81 Alverdy J, Holbrook C, Rocha F, Seiden L, Wu RL, Musch M, et al. Gut-derived sepsis occurs when the right pathogen with the right virulence genes meets the right host: evidence for in vivo virulence expression in Pseudomonas aeruginosa. Ann Surg $2000 ; 232: 480-9$

82 Schultz KF, Chalmers I, Hayes RJ, Altman DG. Empirical evidence of bias: dimension of methodological quality associated with estimates of treatment effects in controlled trials. JAMA 1995;273:408-12.

(Accepted 2 April 2004)

doi $10.1136 /$ bmj.38118.593900.55

Department of Critical Care Medicine, University of Pittsburgh Medical Center, Pittsburgh, PA 15261, USA

Paul E Marik professor of critical care medicine

Methodist Research Institute, Indianapolis, IN 46202, USA

Gary P Zaloga medical director

Correspondence to: P Marik maripe@ccm.upmc.edu 